\title{
Urban public transport optimization by bus ways: a neural network-based methodology
}

\author{
M. Migliore \& M. Catalano \\ Department of Transportation Engineering, Palermo University, Italy
}

\begin{abstract}
This paper describes an approach for planning the introduction of bus lanes into the urban road network, which has been applied to the urban area of Palermo. The proposed modelling tool adopts a multi-agent objective function expressing the trade-off between the interests of diverse stakeholders: the generalized transport cost for car drivers and the travel time for public transport users. The reaction of car traffic to a certain planning scenario has been simulated by the DUE assignment technique and the positive impact of the modal shift on the objective function has been tackled by attaching a suitable weight to the time saving for bus passengers. The rise in the bus travel speed, owing to the bus lane solution, has been predicted for a set of urban roads by a neural network, so as to take into account many quantitative and qualitative road attributes. The optimal location pattern of bus ways has been searched by a greedy heuristic that through a step-by-step strategy builds the problem solution by keeping, at each stage, the best alternative.

Keywords: urban public transport, bus way design, welfare function optimization, neural network, greedy heuristic.
\end{abstract}

\section{Introduction}

Bus lanes represent an effective tool for buses to bypass the congestion at critical sections of the urban road network, especially during rush hours. Furthermore, they consist in a transport policy action that can be easily implemented.

In detail, bus lanes imply the following advantages:

- A rise in the bus travel speed, generally speaking, from $10 \mathrm{Km} / \mathrm{h}$ to $13-15$ $\mathrm{Km} / \mathrm{h}$.

- The punctuality of the public transport service. 
- Comfort and safety improvements, thanks to the reduction in accelerations and decelerations (stop and go driving).

- A decrease in the environmental impact and energy consumptions.

\section{The mobility system of Palermo}

The General Urban Transport Plan of Palermo estimates the internal movements at 960000 travellers per day; the $81 \%$ of such mobility demand uses the car, whereas the residual part chooses the public transport, which highlights a critical situation for Palermo, since, generally speaking, with reference to the public transport share, statistics show a $18 \%-30 \%$ range in the case of small/mediumsized towns and values higher than $50 \%$ in the big town case.

Moreover, the average travel speed on the urban road network is $18 \mathrm{~km} / \mathrm{h}$, while, inside the centre, the travel speed can't be over the $7 \mathrm{~km} / \mathrm{h}$ level, during rush hours.

Other alarming data regard the number of accidents per annum within the urban area of Palermo that comes to about 2000.

In order to reverse this trend, the local administrators have recently launched the Integrated Plan of Transport, for a more effective public transport system, which suggests the bus lane system enhancement (Palermo City Council [1]).

\section{Problem definition and model framework}

The research activity presented has consisted in developing a quantitative methodology for planning the introduction of bus ways into the urban road network. The resulting approach has been applied to Palermo city: the present bus lane system has been compared with the model-based one.

In particular, to identify the study area within Palermo and to select the roads for the bus lane design model, the authors have considered parameters concerning the public transport level of service, number of lines and frequency, and geometric parameters such as the road width.

The considered planning problem has been solved using an objective function representing the trade-off between the interests of private transport users and public transport ones:

$$
O . F .=f\left(\Delta C_{c a r}, \Delta T_{c a r}, \Delta T_{b u s}\right)
$$

where,

$\Delta C_{c a r}$ : rise in the transport monetary cost for car users;

$\Delta T_{c a r}$ : rise in the travel time for car users;

$\Delta T_{\text {bus }}$ : reduction in the transit time for bus users.

The choice behaviour of car drivers has been simulated through the DUE assignment method (Cascetta [2]). 
The effect of bus ways on the bus travel speed has been evaluated by a neural network (Bishop [3]), allowing for several road attributes.

The authors have also considered the positive impact of the modal shift on the local community welfare by assigning a suitable weight to the time saving for bus passengers.

The optimal set of bus ways has been determined through iterations of a greedy algorithm (Tadei and Della Croce [4]).

\section{Solution process}

\subsection{The input for the bus lane design model}

To set the potential sites for bus lanes, the authors have selected those roads respecting the following criteria:

- $\quad$ one regarding the width of the road section for buses;

- $\quad$ another one consisting in the frequency of the public transport service.

In Table 1, the reader can analyze a matrix reporting the different transport policy actions that the authors propose for various combinations of the aforesaid criteria.

Table 1: Transport policy actions based on the public transport level of service and road parameters.

\begin{tabular}{|c|c|c|}
\hline \multicolumn{2}{|c|}{ Criteria } & \multirow[b]{2}{*}{ Transport policy action } \\
\hline $\begin{array}{l}\text { Public transport } \\
\text { frequency, F } \\
\text { (buses per hour) }\end{array}$ & $\begin{array}{l}\text { Width of the road section } \\
\text { for buses, } L^{*} \text { (meters) }\end{array}$ & \\
\hline $\mathrm{F} \geq 21$ & $\mathrm{~L} \geq 5$ & Bus lane \\
\hline $\mathrm{F} \geq 21$ & $\mathrm{~L}<5$ & Closed to traffic zone \\
\hline $12 \leq \mathrm{F}<21$ & $\mathrm{~L} \geq 5$ & $\begin{array}{l}\text { The bus lane solution } \\
\text { is to be weighed }\end{array}$ \\
\hline $12 \leq \mathrm{F}<21$ & $\mathrm{~L}<5$ & No action \\
\hline$F<12$ & & No action \\
\hline
\end{tabular}

It excludes the space for car parking.

\subsection{The estimation of the objective function's components}

As stated before, the optimal bus lane system for Palermo has been searched adopting the following multi-agent objective function:

$$
O . F .=f\left(\Delta C_{c a r}, \Delta T_{c a r}, \Delta T_{b u s}\right)
$$


In detail:

$$
\begin{gathered}
\Delta C_{\text {car }}=[\text { euros per car }-\mathrm{km} \cdot \Delta \mathrm{cars}-\mathrm{km}] \\
\Delta T_{\text {car }}=[\text { euros per car }- \text { hour } \cdot \Delta \text { cars }- \text { hour }] \\
\Delta T_{\text {bus }}=[\text { euros per bus passenger }- \text { hour } \cdot \Delta \text { bus passengers }- \text { hour }] .
\end{gathered}
$$

where,

$\Delta$ cars-km: variation of the cars- $\mathrm{km}$ variable owing to the introduction of bus ways. Such quantity refers to the number of private vehicles moving on the network and the distances covered by themselves.

Acars-hour: variation of the cars-hour variable arising from a certain bus lane pattern. This variable measures the transit time spent by private vehicles.

Abus passengers-hour: variation of the passengers-hour variable arising from a certain bus lane pattern. This variable measures the transit time spent by bus users.

\subsubsection{The determination of $\Delta$ bus passengers-hour}

To compute $\Delta b u s$ passengers-hour, two elements need to be evaluated: the public transport travel speed for the roads under analysis (namely, the potential locations for bus ways) and, for each of these ones, the number of the public transport customers.

In particular, to predict the public transport travel speed, the authors have adopted a neural network, whose architecture is the multilayer perceptron one (Bishop, [3]). In detail, a three layer structure has been used:

- Input layer: with a number of neurons equal to the one of the variables observed for a generic road section. It transfers input data to the processing layer through linear mathematical functions.

- Hidden layer: the computing core of the neural network with a number of neurons determined by the pruning approach. It employs the tanh transfer function.

- Output layer: with a neuron for estimating the bus travel speed.

Such an artificial intelligence tool processes empirical data regarding the following quantitative and qualitative road attributes: bus way availability $(\mathrm{Y} / \mathrm{N})$; number of bus stops; number of junctions with traffic lights; number of side roads; number of pedestrian crossings; possibility of parking with the line of march $(\mathrm{Y} / \mathrm{N})$; transgression of the parking rules $(\mathrm{Y} / \mathrm{N})$; presence of shops $(\mathrm{Y} / \mathrm{N})$; traffic flow/road capacity (La Franca et al [5]).

On the basis of the above-listed variables, the urban roads under analysis have been subdivided into homogeneous sections.

Moreover, the aforesaid empirical road data have been normalized, to be processed by the neural network as dimensionless and comparable inputs.

In order to calculate the number of bus passengers, the origin-destination matrix representing the public transport demand of Palermo during the peak hour of a working day (2002) has been assigned to the corresponding graph by the 
hyperpath minimum algorithm, taking into account the rise of the bus travel speed, due to the introduction of bus lanes (Cascetta [2]).

The output of the described $\Delta b u$ s passengers-hour estimation process can be analyzed in Tables 2 and 3:

Table 2: $\quad$ The neural network-based output.

\begin{tabular}{|c|c|c|c|c|}
\hline Road name & Sections & $\begin{array}{c}\text { Length } \\
(\mathrm{km})\end{array}$ & $\begin{array}{c}\text { Bus speed } \\
\text { without } \\
\text { bus lane } \\
(\mathrm{Km} / \mathrm{h})\end{array}$ & $\begin{array}{c}\text { Bus speed } \\
\text { with } \\
\text { bus lane } \\
(\mathrm{Km} / \mathrm{h})\end{array}$ \\
\hline \multirow{5}{*}{ Via Notarbartolo } & 1 & 0.15 & 6.57 & 14.58 \\
\hline & 2 & 0.25 & 7.07 & 7.57 \\
\hline & 3 & 0.25 & 6.31 & 7.96 \\
\hline & 4 & 0.2 & 7.88 & 15.06 \\
\hline & 5 & 0.15 & 6.28 & 13.75 \\
\hline \multirow{4}{*}{ Viale Lazio } & 1 & 0.25 & 7.00 & 7.10 \\
\hline & 2 & 0.3 & 6.98 & 10.46 \\
\hline & 3 & 0.24 & 6.31 & 9.77 \\
\hline & 4 & 0.24 & 6.52 & 8.16 \\
\hline \multirow{4}{*}{ Via Basile } & 1 & 0.70 & 14.12 & 16.37 \\
\hline & 2 & 0.35 & 15.09 & 15.94 \\
\hline & 3 & 0.50 & 9.84 & 15.99 \\
\hline & 4 & 0.45 & 11.38 & 15.17 \\
\hline \multirow{4}{*}{ Via Dante } & 1 & 0.3 & 5.94 & 11.77 \\
\hline & 2 & 0.15 & 5.88 & 9.16 \\
\hline & 3 & 0.4 & 6.08 & 11.09 \\
\hline & 4 & 0.35 & 7.91 & 8.77 \\
\hline \multirow{4}{*}{ Via Ponte di Mare } & 1 & 0.27 & 9.22 & 15.94 \\
\hline & 2 & 0.47 & 7.66 & 15.15 \\
\hline & 3 & 0.38 & 7.55 & 8.89 \\
\hline & 4 & 0.47 & 7.88 & 13.56 \\
\hline
\end{tabular}

\subsubsection{The determination of $\Delta$ cars- $\mathbf{k m}$ and $\Delta$ cars-hour}

To appraise $\Delta$ cars-km and $\Delta$ cars-hour, the origin-destination matrix representing the private transport demand of Palermo during the peak period of a working day (2002) has been assigned by the DUE approach to the corresponding graph, taking into account the reduction in space for car movements, due to the introduction of bus lanes.

\subsection{Computational results}

This section shows the outcomes achieved by the greedy algorithm (Tadei and Della Croce [4]) applied to determine the optimal set of bus ways for the public transport system of Palermo. 
Table 3: $\quad$ The neural network-based output.

\begin{tabular}{|c|c|c|c|c|}
\hline \multirow{2}{*}{ Road name } & Sections & $\begin{array}{c}\text { Length } \\
(\mathrm{km})\end{array}$ & $\begin{array}{c}\text { Bus speed } \\
\text { without } \\
\text { bus lane } \\
(\mathrm{km} / \mathrm{h})\end{array}$ & $\begin{array}{c}\text { Bus speed } \\
\text { with } \\
\text { bus lane } \\
(\mathrm{km} / \mathrm{h})\end{array}$ \\
\hline \multirow{2}{*}{ Corso Alberto Amedeo } & 1 & 0.2 & 6.44 & 13.64 \\
\cline { 2 - 5 } & 2 & 0.4 & 9.86 & 15.81 \\
\hline \multirow{3}{*}{ Corso Tukory } & 1 & 0.2 & 11.72 & 12.20 \\
\cline { 2 - 5 } & 2 & 0.2 & 13.51 & 12.54 \\
\cline { 2 - 5 } & 3 & 0.2 & 9.51 & 15.74 \\
\cline { 2 - 5 } & 4 & 0.15 & 6.74 & 14.52 \\
\hline \multirow{2}{*}{ Via Duca della Verdura } & 1 & 0.35 & 7.54 & 11.16 \\
\hline \multirow{3}{*}{ Via Marchese di Villabianca } & 1 & 0.4 & 7.04 & 15.06 \\
\cline { 2 - 5 } & 2 & 0.2 & 6.36 & 14.02 \\
\cline { 2 - 5 } & 1 & 0.1 & 7.15 & 14.84 \\
\cline { 2 - 5 } & 2 & 0.15 & 6.04 & 9.09 \\
\cline { 2 - 5 } & 3 & 0.25 & 5.95 & 10.02 \\
\cline { 2 - 5 } & 5 & 0.15 & 7.07 & 13.39 \\
\hline & 6 & 0.15 & 9.70 & 13.80 \\
\hline
\end{tabular}

The above-mentioned heuristic constructs the bus lane design problem solution through a step-by-step optimization process and the following objective function:

$$
W . F .=\alpha(\Delta b u s \text { passengers-hour }-\Delta \text { cars-hour })-\beta \Delta \text { cars- } k m
$$

where,

W.F.: Welfare Function

$\alpha$ : value of time (2.6 euros per passenger-hour)

$\beta$ : private transport cost $(0.1$ euros per car $-\mathrm{km})$

The value of time characterizing the mobility system of Palermo can be estimated at 2 euros/hour. Such a figure has been multiplied by 1.3, so as to take into account, on one hand, the positive environmental impact of a more competitive public transport service and, on the other hand, the need of turning Acars-hour into $\Delta$ car passengers-hour; in fact, the private transport occupancy factor for Palermo can be appraised at 1.3 travellers per vehicle (Palermo City Council [1]). As a consequence:

$$
\begin{gathered}
W . F .=(2 \text { euros per hour }) \cdot 1.3 \cdot(\Delta \text { bus passengers-hour }-\Delta \text { cars-hour }), \\
-(0.1 \text { euros per car-km) } \cdot \Delta \text { cars-km. }
\end{gathered}
$$

The optimal set of bus ways has been built by a sequential approach: at each stage $t(t=1,2, \ldots, \mathrm{N})$, amongst the available roads with a critical public 
Table 4: The comparison between the pre-existent bus way network of Palermo and the model-based one.

\begin{tabular}{|l|c|c|}
\hline \multicolumn{1}{|c|}{ Road name } & $\begin{array}{c}\text { The present bus lane } \\
\text { system of Palermo }\end{array}$ & The model output \\
\hline Corso Tukory & $\bullet$ & $\bullet$ \\
\hline Via Dante (first section)* & - & $\bullet$ \\
\hline $\begin{array}{l}\text { Via Dante (second and third } \\
\text { sections) }\end{array}$ & - & $\bullet$ \\
\hline Via Duca Della Verdura & $\bullet$ & $\bullet$ \\
\hline Via Goethe & - & $\bullet$ \\
\hline Via Libertà* & $\bullet$ & $\bullet$ \\
\hline Via Maqueda* & $\bullet$ & $\bullet$ \\
\hline Via Marchese di Villabianca & - & $\bullet$ \\
\hline Via Notarbartolo & $\bullet$ & $\bullet$ \\
\hline Via Oreto* & - & $\bullet$ \\
\hline Via Ponte di Mare & - & $\bullet$ \\
\hline Via Roma* & $\bullet$ & $\bullet$ \\
\hline Viale Lazio & - & $\bullet$ \\
\hline Viale Strasburgo* & $\bullet$ & $\bullet$ \\
\hline Via Ernesto Basile & - & - \\
\hline Corso Alberto Amedeo & $\bullet$ & - \\
\hline
\end{tabular}

-: with a bus lane; -:without a bus lane.

*: roads with a so high bus frequency that they have been assigned a bus way out of the model.

transport frequency (lying between 12 and 21 buses/hour; see Table 1), the algorithm identifies the one maximizing the Welfare Function by the introduction of a bus lane. In formal terms:

1. $t=1$

2. $\operatorname{Max}_{\boldsymbol{x}^{t}} W \cdot F \cdot\left(\boldsymbol{x}^{t}\right)$, subject to $\sum_{k} x_{k}=1$

3. If $\max _{\boldsymbol{x}^{t}} W \cdot F \cdot\left(\boldsymbol{x}^{t}\right) \leq 0$ then stop

4. $\quad$ Else $\overline{\boldsymbol{x}}^{t}=\arg \max W . F .\left(\boldsymbol{x}^{t}\right)$

5. $t=t+1$

6. $\operatorname{Max}_{\boldsymbol{x}^{t}} W . F \cdot\left(\boldsymbol{x}^{t}+\sum_{j=1}^{t-1} \overline{\boldsymbol{x}}^{j}\right)$, subject to $\sum_{k} x_{k}=1$ and $\boldsymbol{x}^{t} \neq \overline{\boldsymbol{x}}^{j}, j=1$, $2, \ldots, t-1$ 


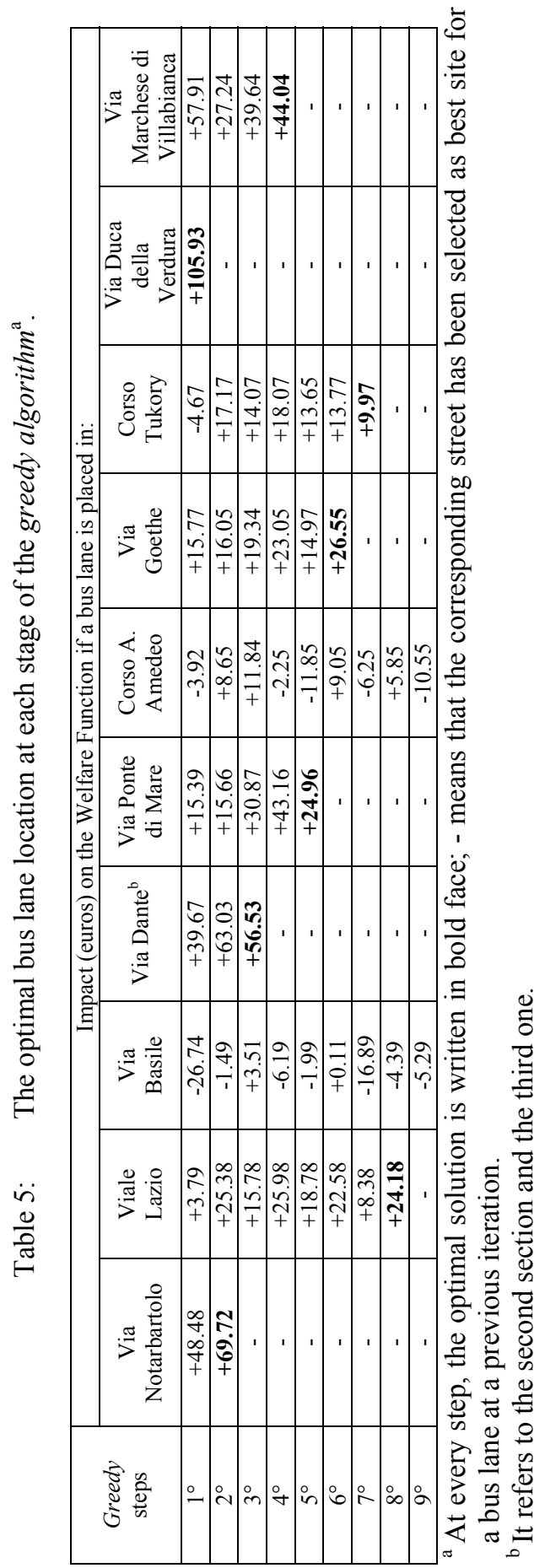


7. If $\max _{\boldsymbol{x}^{t}} W \cdot F \cdot\left(\boldsymbol{x}^{t}+\sum_{j=1}^{t-1} \overline{\boldsymbol{x}}^{j}\right) \leq 0$ or $t=\mathrm{N}$ then stop

8. Else $\overline{\boldsymbol{x}}^{t}=\underset{\boldsymbol{x}^{t}}{\arg \max } W . F \cdot\left(\boldsymbol{x}^{t}+\sum_{j=1}^{t-1} \overline{\boldsymbol{x}}^{j}\right)$

9. Go to step 5 .

where,

$\boldsymbol{x}$ : vector representing the location pattern of bus lanes, whose generic element is $x_{k}$ belonging to the set of those roads with a critical public transport frequency (lying between 12 and 21 buses/hour);

$x_{k}: 1$ if road $k$ is provided with a bus way; 0 otherwise.

As for the application output, the reader can notice in Table 5 that the greedy algorithm stops at the eighth iteration, since at the ninth step, each of the available alternatives (Via Ernesto Basile and Corso Alberto Amedeo) entails a negative value of the objective function.

\section{Conclusions}

A clear proof of the described methodology utility emerges from the outcome showed in Table 5. In fact, consider the Corso Alberto Amedeo case (see Table 3): the public transport is characterized by an average demand of 440 passengers per hour and an average travel speed of $8.15 \mathrm{~km} / \mathrm{h}$; thanks to a bus lane, the average speed level of $14.72 \mathrm{~km} / \mathrm{h}$ can be gained, which means a remarkable $81 \%$ rise. Consequently, the bus lane for Corso Alberto Amedeo seems to be an opportune tool to improve the public transport performance; on the contrary, under an overall point of view concerning the urban mobility system, the illustrated planning model excludes the bus way solution for Corso Alberto Amedeo.

Furthermore, the comparison between the present bus lane system of the study area and the one resulting from the described methodology proves that the former that is based on a qualitative planning approach needs to be highly developed as it has been showed in this paper (see Table 4).

\section{References}

[1] Palermo City Council, Final Report Urban Transport Plan, 2002.

[2] Cascetta, E., Transportation Systems Engineering: Theory and Methods, Dordrecht (The Netherlands): Kluwer Academic Publishers, 2001.

[3] Bishop, C. M., Neural Network for Pattern Recognition, Oxford University Press, Oxford, 1995.

[4] Tadei, R., Della Croce, F., Ricerca Operativa e Ottimizzazione, Esculapio, Bologna, 2001. 
356 Urban Transport XIII: Urban Transport and the Environment in the 21st Century

[5] La Franca, L., Migliore, M., Salvo, G., Carollo, F., The automatic vehicle monitoring to improve the urban public transport management, Proc. of the World Congress CODATU XI Towards More Attractive Urban Transportation, Bucarest, 2004. 